\title{
Consequences of Different Hysterectomy Techniques in Sexual Behavior-A Systematic Review
}

\author{
Ana Fátima Fernandes, Ana Izabel Nicolau, Camila Vasconcelos, Pricilla Alves, \\ Ana Karina Pinheiro, Namie Sawada, Cristina Maria Galvão, Camila Moreira \\ Department of Nursing, Federal University of Ceará, Fortaleza, Brazil \\ Email: afcana@ufc.br
}

Received 23 March 2014; revised 16 April 2014; accepted 23 April 2014

Copyright (C) 2014 by authors and Scientific Research Publishing Inc.

This work is licensed under the Creative Commons Attribution International License (CC BY). http://creativecommons.org/licenses/by/4.0/

\begin{abstract}
We conducted a systematic review of the literature to determine the influence of different hysterectomy techniques in the sexual behavior of women who underwent. We searched CENTRAL (The Cochrane Library), PubMed, SCOPUS, CINAHL and LILACS for studies between the years 1998 and 2010 that prospectively examined the sexuality after hysterectomy. Those that were not randomized controlled clinical trials were excluded. It was not available electronically, it was not related with the outcomes determined, it was not research, but publications before 1998 and study which women realized chemotherapy and radiotherapy. From the 455 identified studies, 9 met inclusion criteria. There was variability in how hysterectomies influence in the sexual behavior. Most of studies considered women who underwent vaginal hysterectomy had fewer changes in sexual behavior. Sexual desire, intercourse frequency and orgasm are the sexual aspects reported by women as more changes experimented after surgery. Findings from this study have implications for healthcare providers and policymakers. Each woman needs an individualized care plan that fits within the context of her life, and there are basic interventions that every woman who underwent hysterectomy should receive. This review draws attention to the need for different care plans for women who underwent different hysterectomy techniques.
\end{abstract}

\section{Keywords}

Hysterectomy; Sexual Behavior; Sistematic Review

\section{Introduction}

Hysterectomy is one of the most common surgical procedures performed on women and there are three main

How to cite this paper: Fernandes, A.F., et al. (2014) Consequences of Different Hysterectomy Techniques in Sexual Behavior-A Systematic Review. Open Journal of Obstetrics and Gynecology, 4, 333-341.

http://dx.doi.org/10.4236/ojog.2014.46050 
surgical approaches: abdominal, vaginal and laparoscopic that can be total or subtotal [1] [2]. It is estimated that by the age of 64 years, $40.5 \%$ women will have had a hysterectomy [3]. Most hysterectomy is done to control or eliminate symptoms and therefore improve quality of life [4].

The majority of patients who undergo hysterectomy are for benign gynecological conditions that often cause significant sexual problems, dyspareunia, chronic pelvic pain, and psychological difficulties [5]-[7]. When hysterectomy is considered the best treatment, there is debate whether subtotal hysterectomy, in which the cervix is preserved, has any advantage over total hysterectomy, in which both the cervix and the uterus are removed [8][11].

The uterus plays a role in the physiological and psychological sexual function of women, being hysterectomy an event that occurs at one point in the continuum of a woman's life [12]. Considering these aspects, the inconclusive results from previous studies and the suggestions of some authors about conduction of more systematic reviews about the thematic, we decided to realize this review to analyze most of realized studies and try to elucidate the consequences of different hysterectomy techniques in the sexual behavior.

This article provides a systematic review of the published literature on different surgical approaches (total or subtotal abdominal, vaginal, laparoscopic influence the sexual behavior of women who underwent).

\section{Method}

The databases searched were CENTRAL (The Cochrane Library), PubMed, SCOPUS, CINAHL and LILACS, being the limits articles published since 1998 and studies in English, Portuguese and Spanish. We searched the studies in the following electronic databases using MeSH's and DeCS' descriptors "hysterectomy" OR "hysterectomy, vaginal” ("histerectomia” OR "histerectomia, vaginal”) AND "sexual behavior" OR "sexuality” (“comportamento sexual OR sexualidade).

The bibliographies from the identified references were also reviewed to identify additional relevant studies. We identified 455 records through database searching. After analyze of abstracts were selected 27 studies and excluded 433. Duplicate records were identified and removed, leaving 9 records for consideration (Figure 1).

\section{Study Selection}

We considered all published studies that assessed different surgical approaches (total or subtotal abdominal, vaginal, laparoscopic) that influence the sexual behavior of women who underwent. We included all published randomized controlled clinical trials and systematic reviews comparing different methods hysterectomy with each other or different techniques of hysterectomy with control groups (with uterus) and your influence in the sexuality, the studies should be available electronically and in the English, Portuguese or Spanish language. We excluded studies were published before 1998 due to a systematic review involving studies published between 1967 and 1997 conducted by Farrell and Kieser [13] about sexuality after hysterectomy.

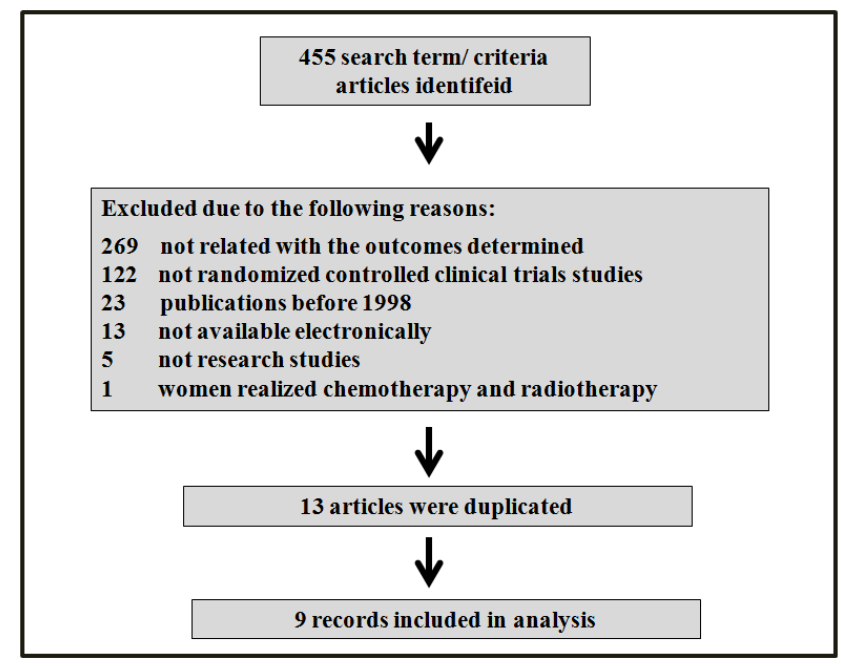

Figure 1. Study search and selection. 
We selected the outcomes to measure considering that it is predictors in sexuality: sexual desire, sexual activity, orgasm and dyspareunia.

All decisions were discussed and reviewed by the authors. A full text version of those studies deemed to be potentially qualifying for inclusion was then obtained and authors established whether each individual study met the inclusion criteria or not in consensus. To extract data from the reviewed articles, a previously validated instrument was used with permission [14], which allowed recording of: methodological characteristics, methodological rigor, intervention type and results. We extracted information on the study design, participants, interventions, outcomes, study quality and the main results of the study.

In addition, a Jadad score [15] was assigned by each reviewer to each study to provide a measure of methodological quality. This measure is a reliable indicator of trial quality and is based on each trial's reporting and quality of randomisation, blinding and attrition. For each study, the primary reviewer allocated or subtracted points in each of these areas according to the Jadad protocol [15]. Thus, the maximum score of the clinical trial quality assessment is 5 . Scores were cross-checked between the primary reviewers and resolved by consensus. The findings were revised with the original reviewers to validate the interpretation of the results and generate recommendations. The data were synthesized through of studies characteristics.

\section{Results}

The 9 studies included in this review [12] [16]-[23] were published between 2002 and 2008. All the nine studies examined the sexuality after hysterectomy. Six of them have compared the effects of hysterectomy between two groups with different techniques of hysterectomy, and only three of the hysterectomy group compared with other types of treatment, which have intact uterus (Table 1).

The articles describe various variables used to analyze sexuality after hysterectomy. Thus, the variables in common were selected for comparison. The most commonly used measure of sexuality after hysterectomy was the assessment of sexual intercourse frequency, orgasm, pain during the sexual intercourse and sexual desire (Table 2).

The quality assessment of studies using the Jadad's score [15] indicates that most of them are classified as good (score $=3-4$ ) and excellent (score = 5). In all articles the instruments were administered before and after intervention. Only one study examined sexuality of six months after surgery. All others had a minimum postoperative follow-up of 12 months. The assessment of any aspect of sexuality must be made with validated and reproducible measurement instruments. Several instruments for assessing sexuality are available [24]-[26], however two studies did not describe the instruments used for assessment of sexuality, nor whether they were validated, which complicates the analysis of the reliability of results and to conduct other studies (Table 3).

Farrell and Kieser [13] in their systematic review, grouped the confounding factors that may influence sexuality controlled by studies in five categories: relationship with partner, hormonal effects, sociopsychological wellbeing, indication for surgery, and type of surgery. In this review, the control for confounding variables was strong (more than 50\%) in the most of studies (Table 4).

The findings about the effect of hysterectomy on sexuality are presented in Table 5 . The studies used different measures to assess each of the variables related to sexuality, which difficult makes comparison between them. However, in all the variables were measured before and after the intervention, revealing its effects. Another difficulty in assessing the results of the studies is that often it is mentioned that only certain variable was not related to the type of intervention evaluated by the study, without showing the figures.

\section{Discussion}

Hysterectomy is common surgical procedures performed on women. The quality of a woman's sexuality before and after hysterectomy is influenced by many factors, the relative importance of which is difficult to quantify. The factors that contribute positively to sexual function include a healthy relationship with a partner, good general health of both partners, freedom from severe life stresses, and absence of financial worry. A change in any of these factors can upset personal equilibrium resulting in a temporary or permanent impairment of sexuality [12].

As regards the type of surgery, we could identify vaginal hysterectomy is less invasive than the abdominal once dispensation the abdominal incision, it can be performed without general anesthesia, with less surgical time, which certainly reduces operative risks, has a better prognosis after surgery which favors less interference in the 
Table 1. Clinical Trials (CT) identification.

\begin{tabular}{|c|c|c|c|c|}
\hline Reference, Year & $\mathrm{N}$ & Compared groups & Type of surgery & Type of hysterectomy \\
\hline \multirow[t]{2}{*}{ Thakar et al., 2002} & 91 & Hysterectomy & Abdominal laparoscopic & Subtotal \\
\hline & 86 & Hysterectomy & Abdominal laparoscopic & Total \\
\hline Total & 177 & & & \\
\hline \multirow[t]{2}{*}{ Ellsrom et al., 2003} & 38 & Hysterectomy & Abdominal laparoscopic & Total \\
\hline & 36 & Hysterectomy & Abdominal laparoscopic & Total \\
\hline Total & 74 & & & \\
\hline \multirow[t]{2}{*}{ Zobbe et al., 2004} & 161 & \multirow{3}{*}{$\begin{array}{l}\text { Hysterectomy } \\
\text { Hysterectomy }\end{array}$} & Abdominal laparoscopic & Subtotal \\
\hline & 158 & & Abdominal laparoscopic & Total \\
\hline Total & 319 & & & \\
\hline \multirow[t]{2}{*}{ Kuppermann et al., 2004} & 31 & \multirow{3}{*}{$\begin{array}{l}\text { Hysterectomy } \\
\text { MT }^{\mathrm{a}}\end{array}$} & \multirow{3}{*}{$\begin{array}{c}\text { No reference } \\
-\end{array}$} & Total \\
\hline & 32 & & & - \\
\hline Total & 63 & & & \\
\hline \multirow[t]{2}{*}{ Kuppermann et al., 2005} & 68 & Hysterectomy & Abdominal laparoscopic & Subtotal \\
\hline & 67 & Hysterectomy & Abdominal laparoscopic & Total \\
\hline Total & 135 & & & \\
\hline \multirow[t]{4}{*}{ Flory et al., 2006} & 32 & Hysterectomy & Vaginal laparoscopic & Total \\
\hline & 31 & Hysterectomy & Abdominal laparoscopic & Subtotal \\
\hline & 30 & SVS $^{\mathrm{b}}$ & Abdominal laparoscopic & - \\
\hline & 40 & $\mathrm{HCNS}^{\mathrm{c}}$ & - & - \\
\hline Total & 133 & & & \\
\hline \multirow[t]{2}{*}{ Hehenkamp et al., 2007} & 75 & Hysterectomy & Abdominal and vaginal (laparoscopic) & Total e Subtotal \\
\hline & 81 & $\mathrm{UAE}^{\mathrm{d}}$ & & \\
\hline Total & 156 & & & \\
\hline \multirow[t]{2}{*}{ Thakar et al., 2008} & 91 & Hysterectomy & Abdominal laparoscopic & Subtotal \\
\hline & 90 & Hysterectomy & Abdominal laparoscopic & Total \\
\hline Total & 181 & & & \\
\hline \multirow[t]{2}{*}{ Gorlero et al., 2008} & 51 & Hysterectomy & Abdominal laparoscopic & Subtotal \\
\hline & 54 & Hysterectomy & Abdominal laparoscopic & Total \\
\hline Total & 105 & & & \\
\hline Total & 1.343 & & & \\
\hline
\end{tabular}

$\mathrm{a}$ = Medicative Treatment; $\mathrm{b}$ = Small Vaginal Surgery; $\mathrm{c}=$ Healthy control Non-Surgical; $\mathrm{d}$ = Uterine Arterial Embolization.

sexual behavior of the woman who undergoes this surgery. This has also been identified in some randomized studies [27] [28].

On the other hand, study with 185 women showed that the type of hysterectomy did not affect the attitudes of respondents ostensibly [29]. Overall, procedural satisfaction reflected the patient's own sense of well-being and sexuality. Neither self-image nor sexuality need diminish in the patient after hysterectomy. It is hoped that these findings offer greater insight in helping women make more informed decisions regarding hysterectomy [29].

As this study shows, Salimena and Souza [30] found that women's sexuality is also considered hysterectomy sexual activity by expressing themselves about sex, sexual intercourse if sex is tranquil and comfortable, or if it caused pain was not possible to resume this practice due to problems after surgery. After hysterectomy, sexual activity proved inherent in daily lives of these women, being practiced or not. There is then the possibility of happening or not happening. In the daily lives of these women, non-resumption occurs: lack of appetite, not practice it before, cannot have relationships, fear of AIDS, are widows, or pain. The recovery also occurs because it is normal to have sex.

Recent attention has focused on sexual functioning after different hysterectomy methods, with numerous reports demonstrating significant improvements in this important domain [18] [31] [32]. However, there are observational studies comparing Total Abdominal Hysterectomy (TAH) and Subtotal Abdominal Hysterectomy 
Table 2. Variables used in studies to assess sexuality.

\begin{tabular}{|c|c|}
\hline Reference, Year & Variables used to assess sexuality \\
\hline Thakar et al., 2002 & $\begin{array}{l}\text { - Intercourse frequency, sexual desire and early sexual intercourse; } \\
\text { - Orgasm frequency, multiple orgasm frequency, vaginal lubrication; } \\
\text { - } \quad \text { Assessment of sexual relationship with the partner; } \\
\text { - Deep and superficial dyspareunia. }\end{array}$ \\
\hline Ellsrom et al., 2003 & $\begin{array}{l}\text { - Intercourse frequency, sexual fantasies frequency; } \\
\text { - Orgasm frequency, sexual pleasure and satisfaction, lubrication, dyspaurenia, } \\
\text { excitement and satisfaction with the partner. }\end{array}$ \\
\hline Zobbe et al., 2004 & $\begin{array}{l}\text { - Intercourse frequency, sexual desire frequency; } \\
\text { - Masturbation frequency, orgasm frequency, orgasm quality, satisfaction with sexual life. }\end{array}$ \\
\hline Kuppermann et al., 2004 & - Sexual desire, orgasm frequency, orgasm quality, sexual satisfaction. \\
\hline Kuppermann et al., 2005 & $\begin{array}{l}\text { - Sexual problems, sexual desire, orgasm; } \\
\text { - Sexual satisfaction. }\end{array}$ \\
\hline Flory et al., 2006 & $\begin{array}{l}\text { - Sexual desire, sexual arousal, orgasm, sexual global functioning, sexual relationship pain, } \\
\text { sexual self-image. }\end{array}$ \\
\hline Hehenkamp et al., 2007 & $\begin{array}{l}\text { - Sexual activity (pleasure, discomfort, habit); } \\
\text { - Sexual life satisfaction, sexual welfare. }\end{array}$ \\
\hline Thakar et al., 2008 & $\begin{array}{l}\text { - Orgasm/multiple orgasm, relationship with partner; } \\
\text { - Vaginal lubrication, deep and superficial dyspareunia. }\end{array}$ \\
\hline Gorlero et al., 2008 & $\begin{array}{l}\text { - Number of sexually active women; } \\
\text { - Pleasure in the sexual act, dyspareunia, sexual habit. }\end{array}$ \\
\hline
\end{tabular}

\section{Table 3. Studies characterization according to instrument used and methodological quality assessment.}

\begin{tabular}{|c|c|c|c|c|}
\hline Reference, Year & Instrument & Validation & Instrument application & Jadad score \\
\hline Thakar et al., 2002 & Questionnaire & Not included & $\begin{array}{ll}- & \text { Before surgery } \\
\text { - } & 6 \text { e } 12 \text { months after }\end{array}$ & 5 \\
\hline Ellsrom et al., 2003 & McCoy scale & Yes & $\begin{array}{l}\text { - } \quad \text { Before surgery } \\
\text { - } 12 \text { months after }\end{array}$ & 1 \\
\hline Zobbe et al., 2004 & Questionnaire & Yes & $\begin{array}{ll}\text { - } & \text { Before surgery } \\
\text { - } & 2 \text { e } 6 \text { months after }\end{array}$ & 3 \\
\hline Kuppermann et al., 2004 & $\begin{array}{l}\text { Combination of } 5 \text { scales and } \\
\text { include new questions }\end{array}$ & Not included & $\begin{array}{l}\text { - } \quad \text { Before surgery } \\
\text { - } 2 \text { years after }\end{array}$ & 3 \\
\hline Kuppermann et al., 2005 & $\begin{array}{l}\text { Medical Outcomes Study (MOS) } \\
\text { Sexual problems scale }\end{array}$ & Yes & $\begin{array}{ll}\text { - } & \text { Before surgery } \\
\text { - } & 6 \text { months and } 2 \text { years after }\end{array}$ & 3 \\
\hline Flory et al., 2006 & $\begin{array}{l}\text { Derogates Interview for Sexual Functioning (DISF) } \\
\text {-Likert Scale } \\
\text { Sexual Self Schema }\end{array}$ & $\begin{array}{c}\text { Yes } \\
- \\
\text { Yes }\end{array}$ & $\begin{array}{l}\text { - } \quad 2 \text { - } 3 \text { weeks before surgery } \\
\text { - } 6 \text { - } 7 \text { years after }\end{array}$ & 3 \\
\hline Hehenkamp et al., 2007 & Sexual Activity Questionnaire (SAQ) & Yes & $\begin{array}{ll}\text { - } & \text { Before surgery } \\
\text { - } & 6 \text { weeks after } \\
\text { - } & 6,12,18 \text { e } 24 \text { months after }\end{array}$ & 4 \\
\hline Thakar et al., 2008 & General Health Questionnaire-28 & Yes & - 7 to 11 years after & 5 \\
\hline Gorlero et al., 2008 & Sexual Activity Questionnaire (SAQ) & Yes & $\begin{array}{l}\text { - } 2 \text { weeks before surgery } \\
\text { - } 12 \text { months after }\end{array}$ & 3 \\
\hline
\end{tabular}


Table 4. Control for confounding factors of sexuality after hysterectomy.

\begin{tabular}{ccc}
\hline Confounding factor & Studies controlling for factor (Total = 09) & $\%$ \\
\hline Age & 08 & 88.8 \\
Socioeconomic status & 03 & 33.3 \\
Education & 04 & 44.4 \\
Race/Ethnicity & 05 & 55.5 \\
Partnership status & 06 & 66.6 \\
Parity & 08 & 88.8 \\
Weight/Body mass index & 07 & 77.7 \\
Menopausal Status & 08 & 88.8 \\
Hormone replacement & 02 & 22.2 \\
\hline
\end{tabular}

Table 5. Control for confounding factors of sexuality after hysterectomy.

\begin{tabular}{|c|c|c|c|c|c|c|c|c|c|c|c|c|c|c|c|c|c|}
\hline \multirow{3}{*}{$\begin{array}{c}\text { Reference, } \\
\text { Year }\end{array}$} & \multirow{3}{*}{$\begin{array}{c}\text { Compared } \\
\text { groups }\end{array}$} & \multicolumn{4}{|c|}{ Sexual relationship } & \multicolumn{4}{|c|}{ sexual desire } & \multicolumn{4}{|c|}{ orgasm } & \multicolumn{4}{|c|}{ Dyspareunia } \\
\hline & & \multicolumn{2}{|c|}{ baseline } & \multicolumn{2}{|c|}{ after } & \multicolumn{2}{|c|}{ baseline } & \multicolumn{2}{|c|}{ after } & \multicolumn{2}{|c|}{ baseline } & \multicolumn{2}{|c|}{ after } & \multicolumn{2}{|c|}{ baseline } & \multicolumn{2}{|c|}{ after } \\
\hline & & g1 & g2 & g1 & g2 & g1 & g2 & g1 & g2 & g1 & g2 & g1 & g2 & g1 & g2 & g1 & g2 \\
\hline \multirow{3}{*}{$\begin{array}{c}\text { Thakar } \\
\text { et al., } \\
2002\end{array}$} & & 73 & 68 & 82 & 69 & & & & & 3.2 & 3.1 & 3.3 & 3.2 & 42 & 33 & 6 & 12 \\
\hline & $\begin{array}{l}\mathrm{G} 1=\mathrm{ASH} \\
\mathrm{G} 2=\mathrm{ATH}\end{array}$ & \multicolumn{2}{|c|}{ NS } & \multicolumn{2}{|c|}{ NS } & \multirow{2}{*}{\multicolumn{2}{|c|}{-}} & \multirow{2}{*}{\multicolumn{2}{|c|}{-}} & \multicolumn{2}{|c|}{ NS } & \multicolumn{2}{|c|}{ NS } & \multicolumn{2}{|c|}{ NS } & \multicolumn{2}{|c|}{ NS } \\
\hline & & \multicolumn{4}{|c|}{ Time effect $p=0.01$} & & & & & & & & & \multicolumn{4}{|c|}{ Time effect $p<0.001$} \\
\hline $\begin{array}{c}\text { Ellsrom } \\
\text { et al., } 2003\end{array}$ & $\begin{array}{c}\mathrm{G} 1=\mathrm{HTA} \\
\mathrm{G} 2=\mathrm{ALTH}\end{array}$ & \multicolumn{2}{|c|}{ NS } & \multicolumn{2}{|c|}{ NS } & & & & & \multicolumn{2}{|c|}{ NS } & \multicolumn{2}{|c|}{ NS } & & & & \\
\hline Zobbe & $\mathrm{G} 1=\mathrm{ASH}$ & $29 \%$ & $34 \%$ & $33 \%$ & $38 \%$ & $39 \%$ & $38 \%$ & $39 \%$ & $44 \%$ & $74 \%$ & $78 \%$ & $77 \%$ & $79 \%$ & $31 \%$ & $32 \%$ & $13 \%$ & $6 \%$ \\
\hline et al., 2004 & $\mathrm{G} 2=\mathrm{ATH}$ & $p=$ & .25 & $p=$ & .33 & $p=$ & 0.94 & $p=$ & 0.24 & $p=$ & .37 & $p=$ & .68 & $p=$ & .71 & $p=$ & .37 \\
\hline Kuppermann & $\mathrm{G} 1=\mathrm{DS}$ & 45 & 56 & 17 & 18 & 41 & 43 & 20 & 07 & 53 & 62 & 12 & 13 & & & & \\
\hline et al., 2004 & $\mathrm{G} 2=\mathrm{MT}$ & $p=$ & .17 & $p=$ & .89 & $p=$ & 0.72 & $p=$ & 0.04 & $p=$ & .38 & $p=$ & .84 & & & & \\
\hline Kuppermann & $\mathrm{G} 1=\mathrm{ASH}$ & 56 & 49 & 72 & 73 & 47 & 39 & 59 & 56 & 65 & 55 & 71 & 69 & & & & \\
\hline et al., 2005 & $\mathrm{G} 2=\mathrm{ATH}$ & $p=$ & .25 & $p=$ & 0.93 & $p=$ & 0.13 & $p=$ & 0.47 & $p=$ & .07 & $p=$ & .47 & & & & \\
\hline & & $28^{*}$ & 33 & $46^{*}$ & 58 & 35 & 37 & 45 & 56 & 29 & 29 & 38 & 53 & 2.4 & 1.4 & 0.0 & 0.5 \\
\hline Flory et al., & $\begin{aligned} \mathrm{G} 1 & =\mathrm{ASLH} \\
\mathrm{G} 2 & =\mathrm{VTLH}\end{aligned}$ & 38 & 38 & 38 & 37 & 45 & 49 & 53 & 40 & 39 & 36 & 42 & 44 & 0.5 & 0.5 & 0.1 & 0.1 \\
\hline 2006 & $\begin{array}{l}\mathrm{G} 3=\mathrm{SVSC} \\
\mathrm{G} 4=\mathrm{HCNS}\end{array}$ & $\mathrm{N}$ & & $p<c$ & .001 & $p=$ & 0.05 & $p<$ & 0.05 & & & & & & & $p=$ & .05 \\
\hline & & & & & $* p<$ & 0.01 & & & & & & & & & & & \\
\hline Hehenkamp & $\mathrm{G} 1=\mathrm{DS}$ & $61 \%$ & $67 \%$ & $61 \%$ & $67 \%$ & & & & & & & 1.1 & 0.8 & & & 0.49 & 0.43 \\
\hline et al., 2007 & G2= UEA & & & $p=$ & .07 & & & & & $p=$ & .76 & $p=$ & .74 & $p=$ & .76 & $p=$ & .88 \\
\hline Thakar & $\mathrm{G} 1=\mathrm{ASH}$ & & & 2 & 2 & & & 3 & 3 & & & 3 & 3 & & & 20 & 31 \\
\hline et al., 2008 & $\mathrm{G} 2=\mathrm{ATH}$ & & & $p=$ & .97 & & & $p=$ & 0.28 & & & & .45 & & & $p=$ & .17 \\
\hline Gorlero & $\mathrm{G} 1=\mathrm{ASH}$ & $64 \%$ & $59 \%$ & $84 \%$ & $70 \%$ & & & & & & & 13 & 15 & & & & \\
\hline et al., 2008 & $\mathrm{G} 2=\mathrm{ATH}$ & & & & & & & & & & & & & & & & \\
\hline
\end{tabular}


(SAH) without conclusions about the effect of hysterectomy in the sexuality, the other study found a decreased in sexual functioning after TAH compared to SAH [33]-[36], while other found no differences between the surgery methods [12].

Thus, sexual intercourse after hysterectomy can be better than before, it can be as it was before or be an obligation of the woman. They expressed a rating of good, bad or better, considering sexual intercourse as possible in the day-to-day. Each of these women has its own expression and particularly involving the partner or not the situation with regard to sexual activity.

A prospective study indentified that women who engaged in sexual relations increased significantly from $70.5 \%$ before hysterectomy to $77.6 \%$ and $76.7 \%$ at 12 and 24 months after hysterectomy [31]. Besides, the rate of frequent dyspareunia dropped significantly from $18.6 \%$ before hysterectomy to $4.3 \%$ and $3.6 \%$ at 12 and 24 months after hysterectomy. The rates of not experiencing orgasms dropped significantly from $7.6 \%$ before hysterectomy to $5.2 \%$ and $4.9 \%$ at 12 and 24 months after hysterectomy. Low libido rates also decreased significantly from $10.4 \%$ before hysterectomy to $6.3 \%$ and $6.2 \%$ at 12 and 24 months after hysterectomy.

About the orgamsm, an American study with 75 women did not find significant changes in sexual desire and frequency, orgasmic frequency, or orgasmic strength after hysterectomy [32]. Most of the patients expected to have no change in desire (53\%), orgasm frequency (76\%), or orgasm strength (67\%) after hysterectomy. However, their findings suggest a significant benefit for patients with pelvic pain and dyspareunia who undergo hysterectomy.

A qualitative study reported that many hysterectomized women would have liked more information on the aftereffects of the operation, including physical, sexual, and emotional aspects [37]. It found negative attitudes seemed to be related to a woman's capacity for childbearing and her sexuality. Other concern centered on the women wanted to feel again their sexual desire, and become sexually active.

Other qualitative study, including 25 men (black 11 and white 14), revealed many men did not know much about hysterectomy and they perceived it had negative effects on women [38]. Some men believed there could be negative effects from the hysterectomy for men as well, including an inability to perform sexually and a change in a man's experience of sexual intercourse. There is no doubt that little change happen after hysterectomy but it is irrelevant when compared to the benefits. Many others studies showed this [39] [40].

\section{Conclusions}

In summary, this review examines the impact of hysterectomy on postoperative sexuality by evaluating the methodologic quality of the literature and highlighting the importance of many confounding factors that are independent of hysterectomy, influence sexuality. Sexual functioning improves overall after hysterectomy. The frequency of sexual activity increases and problems with sexual functioning decrease. The current evidence about the impact of hysterectomy on sexuality is summarized.

The nursing clinical practice must be improved based on these results because it can understand how the different types of hysterectomies surgery will change women's life. As a result, a differentiated care, a specific care plan and therefore more efficient assistance can be offered to the patient.

\section{Conflict of Interest Statement}

None declared.

\section{References}

[1] Johnson, N., Barlow, D., Lethaby, A., Tavender, E., Curr, L. and Garry, R. (2005) Methods of Hysterectomy: Systematic Review and Meta-Analysis of Randomised Controlled Trials. British Medical Journal, 330, 1478. http://dx.doi.org/10.1136/bmj.330.7506.1478

[2] Bronitsky, C., Payne, R.J., Stuckey, S., Wilkins, D. (1993) A Comparison of Laparoscopically Assisted Vaginal Hysterectomy vs Traditional Total Abdominal and Vaginal Hysterectomies. Journal of Gynecologic Surgery, 9, 219-225. http://dx.doi.org/10.1089/gyn.1993.9.219

[3] Ryan, M.M. (1997) Hysterectomy: Social and Psychological Aspects. Baillière’s Clinical Obstetrics and Gynaecology, 11, 23-36. http://dx.doi.org/10.1016/S0950-3552(97)80048-X

[4] Farquhar, C.M. and Steiner, C.A. (2002) Hysterectomy Rates in the United States 1990-1997. Obstetrics \& Gynecology, 99, 229-234. http://dx.doi.org/10.1016/S0029-7844(01)01723-9 
[5] Steege, J.F. (1997) Indications for Hysterectomy: Have They Changed? Clinical Obstetrics and Gynecology, 40, 878885. http://dx.doi.org/10.1097/00003081-199712000-00023

[6] Katz, A. (2003) Sexuality after Hysterectomy: A Review of the Literature and Discussion of Nurses’ Role. Journal of Advanced Nursing, 42, 297-303. http://dx.doi.org/10.1046/j.1365-2648.2003.02619.x

[7] Moorman, P.G., Schildkraut, J.M., Iversen, E.S., et al. (2009) A Prospective Study of Weight Gain after Premenopausal Hysterectomy. Journal of Women's Health, 18, 699-708. http://dx.doi.org/10.1089/jwh.2008.1019

[8] Helstrom, L., Lundberg, P.O., Sorbom, D. and Backstrom, T. (1993) Sexuality after Hysterectomy: A Factor Analysis of Women's Sexual Lives before and after Subtotal Hysterectomy. Obstetrics \& Gynecology, 81, 357-362.

[9] Roovers, J.P., van der Bom, J.G., van der Vaart, C.H. and Heintz, A.P. (2003) Hysterectomy and Sexual Well-Being: Prospective Observational Study of Vaginal Hysterectomy, Subtotal Abdominal Hysterectomy, and Total Abdominal Hysterectomy. British Medical Journal, 327, 774-778. http://dx.doi.org/10.1136/bmj.327.7418.774

[10] Saini, J., Kuczynski, E., Gretz, H.F. and Sills, E.S. (2002) Supracervical Hysterectomy versus Total Abdominal Hysterectomy: Perceived Effects on Sexual Function. BMC Women's Health, 2, 1. http://dx.doi.org/10.1186/1472-6874-2-1

[11] Virtanen, H., Makinen, J., Tenho, T., Kiilholma, P., Pitkanen, Y. and Hirvonen, T. (1993) Effects of Abdominal Hysterectomy on Urinary and Sexual Symptoms. British Journal of Urology, 72, 868-872. http://dx.doi.org/10.1111/j.1464-410X.1993.tb16288.x

[12] Zobbe, V., Gimbel, H., Andersen, B.M., et al. (2004) Sexuality after Total vs. Subtotal Hysterectomy. Acta Obstetricia et Gynecologica Scandinavica, 83, 191-196. http://dx.doi.org/10.1111/j.0001-6349.2004.00311.x

[13] Farrell, S.A. and Kieser, K. (2000) Sexuality after Hysterectomy. Obstetrics and Gynecology, 95, 1045-1051. http://dx.doi.org/10.1016/S0029-7844(00)00784-5

[14] Ursi, E.S. and Galvão, C.M. (2006) Prevenção de lesões de pele no perioperatório: Revisão integrativa da literatura. Rev Latino-am Enfermagem, 14, 124-311. http://dx.doi.org/10.1590/S0104-11692006000100017

[15] Jadad, A.R., Moore, R.A., Carroll, D., Jenkinson, C., Reynolds, D.J.M., Gavaghan, D.J. and McQuay, H.J. (1996) Assessing the Quality of Reports of Randomized Clinical Trials: Is Blinding Necessary? Controlled Clinical Trials, 17, 1-12. http://dx.doi.org/10.1016/0197-2456(95)00134-4

[16] Thakar, R., Ayers, S., Clarkson, P., Stanton, S. and Manyonda, I. (2002) Outcomes after Total versus Subtotal Abdominal Hysterectomy. New England Journal of Medicine, 347, 1318-1325. http://dx.doi.org/10.1056/NEJMoa013336

[17] Ellström, M.A., Åström, M., Möller, A.N.D.E.R.S., Olsson, J.H. and Hahlin, M. (2003) A Randomized Trial Comparing Changes in Psychological Well-Being and Sexuality after Laparoscopic and Abdominal Hysterectomy. Acta Obstetricia et Gynecologica Scandinavica, 82, 871-875.

[18] Kuppermann, M., Varner, R.E., Summitt Jr., R.L., et al. (2004) Effect of Hysterectomy vs Medical Treatment on Health-Related Quality of Life and Sexual Functioning: The Medicine or Surgery (Ms) Randomized Trial. JAMA, 291, 1447-1455. http://dx.doi.org/10.1001/jama.291.12.1447

[19] Kuppermann, M., Summitt Jr., R.L., Varner, R.E., et al. (2005) Sexual Functioning after Total Compared with Supracervical Hysterectomy: A Randomized Trial. Obstetrics \& Gynecology, 105, 1309-1318. http://dx.doi.org/10.1097/01.AOG.0000160428.81371.be

[20] Flory, N., Bissonnette, F., Amsel, R.T. and Binik, Y.M. (2006) The Psychosocial Outcomes of Total and Subtotal Hysterectomy: A Randomized Controlled Trial. The Journal of Sexual Medicine, 3, 483-491. http://dx.doi.org/10.1111/j.1743-6109.2006.00229.x

[21] Hehenkamp, W.J.K., Volkers, N.A., Bartholomeus, W., de Blok, S., Birnie, E., Reekers, J.A. and Ankum, W.M. (2007) Sexuality and Body Image after Uterine Artery Embolization and Hysterectomy in the Treatment of Uterine Fibroids: A Randomized Comparison. Cardiovascular and Interventional Radiology, 30, 866-875. http://dx.doi.org/10.1007/s00270-007-9121-7

[22] Thakar, R., Ayers, S., Srivastava, R. and Manyonda, I. (2008) Removing the Cervix at Hysterectomy: An Unnecessary Intervention? Obstetrics \& Gynecology, 112, 1262-1269. http://dx.doi.org/10.1097/AOG.0b013e31818f3bf5

[23] Gorlero, F., Lijoi, D., Biamonti, M., Lorenzi, P., Pullè, A., Dellacasa, I. and Ragni, N. (2008) Hysterectomy and Women Satisfaction: Total versus Subtotal Technique. Archives of Gynecology and Obstetrics, 278, 405-410. http://dx.doi.org/10.1007/s00404-008-0615-6

[24] Darling, C.A. and McKay-Smith, Y.M. (1993) Understanding Hysterectomies: Sexual Satisfaction and Quality of Life. Journal of Sex Research, 30, 324-335. http://dx.doi.org/10.1080/00224499309551719

[25] Derogatis, L.R. and Melisaratos, N. (1983) The Brief Symptom Inventory: An Introductory Report. Psychological Medicine, 13, 595-605. http://dx.doi.org/10.1017/S0033291700048017

[26] Van den Eeden, S.K., Glasser, M., Mathias, S.D., Colwell, H.H., Parta, D.J. and Kunz, K. (1988) Quality of Life, 
Health Care Utilization, and Costs among Women Undergoing Hysterectomy in a Managed Care Setting. American Journal of Obstetrics \& Gynecology, 178, 91-100. http://dx.doi.org/10.1016/S0002-9378(98)70633-7

[27] Ottosen, C., Lingman, G. and Otossen, L. (2000) Three Methods for Hysterectomy: A Randomised, Prospective Study of Short-Term Outcome. BJOG: An International Journal of Obstetrics \& Gynaecology, 107, 1380-1385. http://dx.doi.org/10.1111/j.1471-0528.2000.tb11652.x

[28] Nezhat, C., Bess, O., Admon, D., Nezhat, C.H. and Nezhat, F. (1994) Hospital Cost Comparison between Abdominal, Vaginal, and Laparoscopy-Assisted Vaginal Hysterectomies. Obstetrics and Gynecology, 83, 713-716.

[29] Roussis, N.P., Waltrous, L., Kerr, A., Robertazzi, R. and Cabbad, M.F. (2004) Sexual Response in the Patient after Hysterectomy: Total Abdominal versus Supracervical versus Vaginal Procedure. American Journal of Obstetrics and Gynecology, 190, 1427-1428. http://dx.doi.org/10.1016/j.ajog.2004.01.074

[30] Salimena, A.M.O. and Souza, I.E.O. (2008) O sentido da sexualidade de mulheres submetidas a histerectomia: Uma contribuição da enfermagem para a integralidade da assistência ginecológica. Escola Anna Nery, 12, 637-644. http://dx.doi.org/10.1590/S1414-81452008000400005

[31] Rhodes, J.C., Kjerulff, K.H., Langenberg, P.W. and Guzinski, G.M. (1999) Hysterectomy and Sexual Functioning. JAMA, 282, 1934-1941. http://dx.doi.org/10.1001/jama.282.20.1934

[32] Dragisic, K.G. and Milad, M.P. (2004) Sexual Functioning and Patient Expectations of Sexual Functioning after Hysterectomy. American Journal of Obstetrics \& Gynecology, 190, 1416-1418. http://dx.doi.org/10.1016/j.ajog.2004.01.070

[33] Cohen, J. (1968) Weighted Kappa: Nominal Scale Agreement Provision for Scaled Disagreement or Partial Credit. Psychological Bulletin, 70, 213-220. http://dx.doi.org/10.1037/h0026256

[34] Kilkku, P., Gronroos, M., Hirvonen, T. and Rauramo, I. (1983) Supra Vaginal Uterine Amputation vs Hysterectomy: Effects on Libido and Orgasm. Acta Obstetricia et Gynecologica Scandinavica, 62, 147-152. http://dx.doi.org/10.3109/00016348309155779

[35] Ruoss, C.F. (1995) Supravaginal Hysterectomy-A Less Invasive Procedure. Journal of Obstetrics \& Gynecology, 15, 406-409. http://dx.doi.org/10.3109/01443619509009175

[36] Lauridsen, L. and Jensen, V.C. (1961) Total Contra Subtotal Hysterektomi. Ugeskr Leger, 123, 298-307.

[37] Williams, R.D. and Clark, A.J. (2000) A Qualitative Study of Women's Hysterectomy Experience. Journal of Women's Health \& Gender-Based Medicine, 9, 15-25. http://dx.doi.org/10.1089/152460900318731

[38] Bernhard, L.A., Harris, C.R. and Caroline, H.A. (1992) Men’s Views about Hysterectomies and Women Who Have Them. Image, 24, 177-181.

[39] Graham, M., James, E.L. and Keleher, H. (2008) Predictors of Hysterectomy as a Treatment for Menstrual Symptoms. Women's Health Issues, 18, 319-327. http://dx.doi.org/10.1016/j.whi.2008.04.001

[40] Skea, Z., Harry, V., Bhattacharya, S., Entwistle, V., Williams, B., MacLennan, G. and Templeton, A. (2004) Women’s Perceptions of Decision-Making about Hysterectomy. BJOG: An International Journal of Obstetrics and Gynecology, 111, 133-142. http://dx.doi.org/10.1046/j.1471-0528.2003.00027.x 